\title{
Father's and mother's beliefs about children's anxiety
}

\author{
Ana Beato (i) | Luísa Barros | Ana Isabel Pereira
}

Faculty of Psychology, University of Lisbon, Lisbon, Portugal

\section{Correspondence}

Ana Beato, Faculdade de Psicologia,

Universidade de Lisboa, 1649-013 Lisbon,

Portugal.

Email: anabeato@campus.ul.pt

\section{Funding information}

Fundação para a Ciência e Tecnologia, Grant/ Award Number: PTDC/PSI-PCL/122007/ 2010 awarded to A. I. Pereira; SFRH/7737/ 2011 awarded to A. Beato

\begin{abstract}
Background: Previous research has focused on parenting styles and parental behaviors associated with children's anxiety. Parental beliefs about their child's anxiety have scarcely been studied, in spite of their probable influence in parents seeking help. The present study intended to fil that gap, by exploring what parents think about their children's anxiety and whether these cognitions are related or not to their use of professional help.
\end{abstract}

Method: In-depth semistructured interviews were conducted with 48 parents (50\% fathers) of children (9-12 years old) with anxiety problems. Theoretical thematic analysis was performed on the transcripts.

Results: Three dimensions were derived from the analysis, concerning (a) the causes of child's anxiety, (b) the impact of anxiety in the child's functioning, and (c) the evolution of anxiety. Most parents perceived the child's anxiety as a permanent condition, attributing it to external and parental factors and considering that the anxiety problems have a negative impact on the child's well-being. Plus, parents who had previously sought professional help for the child's emotional problems tended to believe that anxiety could improve with child's or parents' efforts and with professional guidance, contrarily to those who had not. Implications for research and clinical practice are discussed.

Conclusion: The present study highlighted important parental beliefs about their children's anxiety that might influence their attitudes and decisions (e.g., seek for professional help). Other parental cognitions should be investigated in order to understand parenting in the context of childhood anxiety.

\section{KEYWORDS}

beliefs, children anxiety, fathers, help seeking, mixed methods

\section{1 | INTRODUCTION}

Anxiety disorders have typically an early onset (Keller et al., 1992; Orvaschel, Lewinsohn, \& Seeley, 1995) and are one of the most common emotional disorders experienced by children and adolescents (Essau \& Gabbidon, 2013). Anxiety symptoms are associated with considerable impairment across many contexts of the child's life (Essau, Conradt, \& Petermann, 2000). However, only a minority of children and adolescents gets help from mental health services (Burns et al., 1995). In fact, anxiety disorders during childhood might continue into adulthood and are associated with negative life course outcomes if left untreated (Last, Hansen, \& Franco, 1997; Pine, Cohen, Gurley, Brook, $\&$ Ma, 1998). Consequently, a clear understanding of the mechanisms responsible for anxiety development and maintenance over time is needed in order to promoting effective treatments to those children and adolescents needing intervention.

Family factors are among the most studied mechanisms involved in children's anxiety development and perpetuation over time (Chorpita \& Barlow, 1998; Craske, 1999; Vasey \& Dadds, 2001). Previous research has established a relation between children's anxiety 
and various parenting styles and behaviors, such as overcontrol, negative behaviors, and parental modelling of anxious and avoidant behaviors (see Ginsburg \& Schlossberg, 2002; McLeod, Wood, \& Weisz, 2007; Van Der Bruggen, Stams, \& Bögels, 2008, for reviews).

Despite the emphasis on behavioral and emotional parenting characteristics associated with children's anxiety, the interest in parental cognitive dimensions has been increasing. Most studies about childhood anxiety focused mainly on parental perceptions and expectations about the child (e.g., Micco \& Ehrenreich, 2008), parental perception of control over the child (Wheatcroft \& Creswell, 2007), and beliefs about the harmfulness of anxiety (e.g., Francis \& Chorpita, 2009). In particular, parents of anxious children have specific expectations about their child's anxiety and coping responses. For instance, they anticipate that their children will show poorer coping abilities and be more avoidant, distressed, and unable to comfort themselves when facing stressful situations (Kortlander, Kendall, \& PanichelliMindel, 1997). These parents also hold more beliefs about the harmfulness of the child's anxiety (Francis \& Chorpita, 2009) and perceive themselves to have less control over their child's anxious mood and avoidant behavior (i.e., external parenting locus of control) than parents of nonanxious children (Wheatcroft \& Creswell, 2007).

Despite these advances, there are gaps in the literature. Parental beliefs concerning the causes and the evolution of anxiety and parental perceptions about the impact of children's anxiety have been poorly investigated. From our point of view, this represents a promising research area, as they ascribe meaning to children's behavior and, as such, are theorized to guide parents' behavioral and affective responses to their children (Bugental \& Johnston, 2000; Rudy \& Grusec, 2006). Further, with few exceptions (Ollendick, 1979), most studies failed to analyze parents' beliefs and attributions according to parental gender.

Furthermore, in spite of the empirical evidence of cognitivebehavioral therapy effectiveness for children's anxiety problems (e.g. Cartwright-Hatton, Roberts, Chitsabesan, Fothergill, \& Harrington, 2004; James, James, Cowdrey, Soler \& Choke., 2013), many parents do not seek professional help. Some predictors have been studied regarding parental recognition of their child's emotional or behavioral problems (e.g., their perception of the problem as nonsevere: Angold et al., 1998; Lyneham \& Rapee, 2007) and help seeking (e.g., child's age, the amount of distress or burden parents experience in raising their child, and the existence of related medical or school problems: for a review, see Zwaanswijk, Verhaak, Bensing, van der Ende, \& Verhulst, 2003). In a recent exploratory study with parents of anxious children, Alves (2013) explored parents' motives for not seeking professional help and concluded that many did not recognized anxiety as a problem and considered it as without significant impact or to be a transient issue. Therefore, parental beliefs about the child's anxiety might compromise their decision to seek professional help for their child's anxiety problems in cases where it is needed (e.g., parents who believe that anxiety is caused by external reasons, is transitory, and has no significant impact in the child's life might be less prone to seek professional services).

The present study expanded the existent literature by examining parental beliefs and attributions regarding their child's anxiety and including both caregivers. Five specific questions were addressed: To

\section{Key messages}

- Anxiety disorders are one of the most common mental health problems during childhood with various implications and costs across the lifespan.

- Parents are considered to play an essential role in the development and maintenance of children anxiety.

- This study showed that parents of anxious children tend to explain the causes of anxiety based on external and parental factors.

- Parents perceive anxiety disorders as a problem with negative impact in child's well-being.

- Fathers tend to believe that anxiety is temporary, whereas mothers consider it as a persistent problem.

- Parents who already sought for professional help believed in the amelioration of anxiety with guidance and effort taking.

which causes do parents attribute their child's anxiety, and what are their beliefs about the evolution of their child's anxiety? How do parents perceive the impact of their child's anxiety? Do mothers and fathers have different beliefs and perceptions about anxiety? Do parents who had sought professional help have different beliefs and perceptions about the child's anxiety, compared with parents who did not?

A qualitative research methodology was used in the initial phase, to explore patterns or themes from parent's verbalizations (for a review, see Braun \& Clarke, 2006). Afterwards, a quantitative analysis was done to compare fathers and mothers and two groups of parents (parents who had sought professional help and parents who had not) and answer our last research questions.

\section{2 | METHOD}

\section{1 | Participants}

The sample comprised 48 parents of 35 anxious children (9-12 years old) drawn from a larger study. Half of the sample was constituted by fathers. Fathers' ranged from 31 to 53 years old $(M=41.6$, $S D=5.09$ ), whereas mothers were between 32 and 53 years old $(M=40.5, S D=5.26)$. In terms of parents' educational level, $16.7 \%$ of the fathers completed the ninth grade or less, $54.2 \%$ finished high school grade or tertiary education, and $20.8 \%$ finished college, whereas $45 \%$ of mothers had the ninth grade or less, $20 \%$ finished high school, and $35 \%$ completed college or tertiary education. All parents were married or lived in common law, lived with the child, and were the child's biological parents. The socioeconomic level was relatively well distributed across families (25\% low status, $47.9 \%$ medium status, $22.9 \%$ medium high or high). Children included $57.1 \%$ of girls and ranged between 9 and 12 years old ( $M=10, S D=1.02)$. The principal diagnoses of the anxious children included generalized anxiety 
disorder ( $n=13$ ), social phobia $(n=9)$, specific phobia $(n=8)$, and separation anxiety $(n=5)$. Twenty-two children met criteria for more than one anxiety diagnosis, one for a comorbid mood disorder, and three for a comorbid behavior disorder (oppositional defiant disorder or attention deficit hyperactivity disorder).

\section{2 | Measures}

\subsection{1 | Interview "Anxious to know"}

The qualitative interview followed a semistructured script with openended questions specially developed to this study. The interviews were administered individually and were audio recorded, lasting $45 \mathrm{~min}$ on average. The questions asked to the parents were as follows:

1. In your opinion, which are the causes of your son/daughter's anxiety?

2. When have these symptoms started?

3. How do you think your child's anxiety will evolve?

4. What impact does anxiety have in your son/daughter's life?

5. Have you ever sought any professional help for your child's anxiety problems?

\section{3 | Procedure}

Prior to recruitment and data collection, the project was approved by the National Data Protection Commission, the General Administration for Innovation and Curriculum Development from Portuguese Ministry of Education, and the Ethic Committee of the Faculty of Psychology, University of Lisbon. Informed consent was obtained from all participants.

This study is part of a broader research project that focused on parenting and children's anxiety. The sample was recruited following different phases. First, 55 children from a larger community sample with high scores in a questionnaire measuring children's anxiety problems (Screen for Child Anxiety Related Emotional Disorders-Revised form; Muris, Merckelbach, Schmidt, \& Mayer, 1999) were selected. In the second phase, children and their parents were interviewed to confirm the diagnosis of anxiety (Anxiety Disorders Interview Schedule [ADIS]-Children/Parents version; Silverman \& Albano, 1996). To proceed to the next phase, it was required that the child had not only an anxiety disorder as primary diagnosis but whose parents recognized the negative interference of anxiety in the child's well-being. Finally, the children with a primary diagnosis of anxiety and their parents were invited to participate in a second, semistructured interview ("Anxious to know") to assess parental perspectives on children's anxiety. The current study involved the analyses of these qualitative interviews transcripts. Interviews were conducted in schools or other sites in the families' community. The individual interviews were conducted by the first author, who is a clinical psychologist and has experienced in psychological assessment.

\section{4 | Data analysis}

Interviews were transcribed verbatim and subjected to content analysis. First, familiarizing with the data was accomplished through reading all transcripts to accomplish immersion (Tesch, 1990) and then with more detail to derive codes (Miles \& Huberman, 1994). Second, coding and collating the data included attributing codes to all salient ideas. Third, higher (e.g., causes of anxiety) and second-level themes (e.g., internal, parental, external, combined, and normative factors and unknown causes) were derived from the coded data based on their theoretical and clinical importance. Reviewing and deciding the final themes and sub-themes was a process that included the different coders and their validation by other researchers. The first author and two psychology graduate students independently coded $50 \%$ of the transcript respectively. The three coders attained $90 \%$ of agreement, corresponding to a high reliability. Ambiguities and disagreements were discussed and adjusted among the coders.

The QSR International's NVivo 10 Software (QSR, 2012) was used to store and organize the qualitative material. Afterwards, themes, sub-themes, and sociodemographic data were transformed into nominal variables and entered into an SPSS file. Descriptive statistics were used to obtain the frequencies of parents who have reported each sub-theme. Afterwards, chi-square tests were applied to data to verify if the percentages of fathers and mothers show significant differences in terms of beliefs about causes, evolution, and impact of child's anxiety. The same test was used to compare parents who had previously sought professional help with those who had not, in relation to the themes derived from the previous content analysis.

\section{3 | RESULTS}

Three dimensions were analyzed. Each one was divided into more specific subdimensions (see Table 1 for a summary).

\section{1 | Causes of anxiety}

Most parents attributed their child's anxiety to external causes noncontrolled by parents or the child (see excerpts in Table 2). Negative life experiences were the most mentioned. Most of these life experiences represented specific situations that had occurred in the past in different contexts. Socialization problems, evaluations, teacher's negative comments, bullying, parent's divorce or conflict, losses or separations, and traumatic situations (e.g., being attacked by a dog) were among the experiences referred by parents. Exposure to certain sources of information was also identified as a potential stressor. One father and one mother referred that children were in contact with anxiety provoking information.

On the other hand, many parents mentioned parental factors as causes of the child's anxiety. Distinct mechanisms for anxiety transmission were identified. First, parents' own parenting rearing styles and behaviors (e.g., overprotection and demandingness) were identified by three fathers and two mothers. Parents recognized their own attitudes or their partner's attitudes as relevant contributors to the child's anxiety. Second, three fathers and one mother considered that they were themselves quite anxious and tended to believe that their 
TABLE 1 Proportion of fathers and mothers who referred each subdimension

\begin{tabular}{|c|c|c|c|c|}
\hline Dimension & Subdimension & Fathers & Mothers & Total (\%) \\
\hline Causes of anxiety & $\begin{array}{l}\text { External causes } \\
\text { Parental causes } \\
\text { Combined causes (internal and external or parental) } \\
\text { Internal causes } \\
\text { Normative causes } \\
\text { Unknown causes }\end{array}$ & $\begin{array}{l}9(37.5) \\
7(29.2) \\
4(16.7) \\
1(4.2) \\
2(8.3) \\
1(4.2)\end{array}$ & $\begin{array}{l}7(29.2) \\
5(20.8) \\
7(29.2) \\
3(12.5) \\
2(8.3) \\
0(0)\end{array}$ & $\begin{array}{r}16(33.3) \\
12(25.0) \\
11(22.9) \\
4(8.3) \\
4(8.3) \\
1(2.1)\end{array}$ \\
\hline Evolution of anxiety & $\begin{array}{l}\text { Permanent } \\
\text { Temporary } \\
\text { Improvement by child's effort or external help }\end{array}$ & $\begin{array}{r}6(25) \\
12(50) \\
6(25)\end{array}$ & $\begin{aligned} 12 & (50) \\
4 & (16.7) \\
8 & (33.3)\end{aligned}$ & $\begin{array}{l}18(37.5) \\
16(33.3) \\
14(29.2)\end{array}$ \\
\hline Impact of anxiety & $\begin{array}{l}\text { Negative for the child/family } \\
\text { No impact } \\
\text { Positive for the child }\end{array}$ & $\begin{aligned} 13 & (54.2) \\
9 & (37.5) \\
2 & (8.3)\end{aligned}$ & $\begin{aligned} 15 & (62.5) \\
8 & (33.3) \\
1 & (4.2)\end{aligned}$ & $\begin{array}{c}28(58.3) \\
17(35.4) \\
3(6.3)\end{array}$ \\
\hline
\end{tabular}

TABLE 2 Examples of excerpts of beliefs about causes of anxiety

\begin{tabular}{|c|c|}
\hline Subdimension & Excerpts from the interview \\
\hline External causes & $\begin{array}{l}\text { Her teacher used to say that her homework was all wrong. We were asked to talk with the teacher many times because of } \\
\text { that. (Father, 9-year-old girl) } \\
\text { Maybe anxiety comes from some less positive situations or experiences that might have caused him fear and apprehension. } \\
\text { Now, he is afraid that they might happen again [Father, } 9 \text { years boy]. } \\
\text { I think she got those fears from the television, from cartoons and so on. (Father, 9-year-old girl) }\end{array}$ \\
\hline Parental causes & $\begin{array}{l}\text { My wife protected her too much. She is so attached to all of our children, but especially to this one because she was our first } \\
\text { daughter. (Father, 11-year-old girl) } \\
\text { The mother gives him too much affect and caring. She is not able to provide some balance. (Father, 9-year-old boy) } \\
\text { We let her sleep in our bed for a long time. Her fear of darkness might be somehow related to this. (Father, 9-year-old girl) } \\
\text { Sometimes I just think that it's because we are such overprotective parents. I worry too much about him. (Mother, 10-year- } \\
\text { old boy) } \\
\text { I am a very clean and organized person. She has copied some of these features from me. For instance, all these post-its she } \\
\text { uses ... She saw me doing the very same thing. (Mother, 11-year-old girl) } \\
\text { I think he is afraid of flying because he sees that his mother and his father are too. (Father, 10-year-old boy) } \\
\text { Maybe I influenced her because I was always telling her that these would be her first exams and that having good grades } \\
\text { would be fundamental to move to the next school year. (Mother, 9-year-old girl) }\end{array}$ \\
\hline Internal causes & $\begin{array}{l}\text { It is something that comes from herself. She is too dependent on us. (Mother, 10-year-old girl) } \\
\text { I think anxiety comes from her own sensibility. When I compare her to her sister, I realize they are different. It's just her } \\
\text { temperament; she is too attached to the family. (Mother, 11-year-old girl) }\end{array}$ \\
\hline Combined causes & $\begin{array}{l}\text { Maybe I have given her too much responsibility for a girl her age. She had to take care of her little brother (...) She always } \\
\text { has been very attached to us ... too much! She does not sleep at other people's houses and lacks the courage to cope with } \\
\text { her fears because ... it's in her. She is a very dependent girl. (Mother, 11-year-old girl) } \\
\text { Probably I passed my anxiety to her through my genes. And I might be passing this same worry to her, without being aware } \\
\text { of it. (Father, 11-year-old girl) }\end{array}$ \\
\hline Normative causes & $\begin{array}{l}\text { It's a natural reaction. He sees a dog and is afraid because he thinks the dog will bite him. That's perfectly normal. (Mother, } \\
\text { 10-year-old boy) } \\
\text { It's inevitable. We can't be happy and calm all the time, can we? There will always be something causing anxiety in our lives. } \\
\text { (Mother, 10-year-old girl) }\end{array}$ \\
\hline
\end{tabular}

attitudes and behaviors might have caused the child's anxiety through emotional contagion, modelling, and verbal transmission. Third, one father and one mother mentioned that they were responsible for conveying information that might increase the child's anxiety.

Four parents attributed the child's anxiety to internal factors, considering anxiety as internally driven and stable, inherent to the child's traits, personality, or temperament. Terms such as "sensible," "dependent," "nervous," "anxious," or "preoccupied" were used by these parents to describe their offspring. For a few, their child's anxiety was acquired through genetic or biological influences.

Nearly a quarter of parents attributed their child's anxiety to the complex combination of internal and external or parental factors. Moreover, four parents perceived their children's anxiety as a "normal response" to stressful situations, as part of everyone's experience. One father did not find any reason for his son's anxiety, because he did not recognize the child's anxiety as a problem and had trouble identifying any symptoms.
In sum, most parents attributed the causes of their children's anxiety to external factors, such as negative events or anxiogenic information. Parental-related causes were mentioned by many parents, such as negative parenting and modelling. Mothers and fathers evidenced no significant differences in their beliefs about the causes of child's anxiety, $\chi^{2}(4,48)=3.39, p=0.495$.

\section{2 | Evolution of anxiety}

Eighteen parents, mostly mothers, believed that the child's anxiety is a permanent problem that will not be resolved or disappear (Table 3). Although all these parents considered their children's anxiety to be long-lasting, some differences should be highlighted. One father and three mothers perceived it as a stable condition that will be sustained over time without significant changes. One father and five mothers were more pessimistic and expected anxiety symptoms to worsen with growth, with an increasing interference in 
TABLE 3 Examples of excerpts of beliefs about the evolution of anxiety

Subdimension Excerpts from the interviews
Permanent
His fears won't get worse. They will just remain the same. (Mother, 9-year-old boy)
He will probably become more and more anxious, a sad child. (Father, 9-year-old boy)
She will get used to feel anxious and stressed before the exams. (Father, 11-year-old girl)
Her anxiety will not evolve, such as her mother's anxiety didn't. Human brain functions like that and she will have to control or
get around her anxiety in some way. (Father, 10-year-old girl)
It's the development. Feeling anxious is a normal aspect in our lives, evolution and transition. It comes in waves. It's a cycle.
(Father, 9-year-old boy)
Sincerely, I think this is a phase. These are the natural worries for any child. When he gets a bit older and interact more with
friends, he will feel less nervous and insecure. (Father, 9-year-old boy)
I think these will pass with age. But I will also encourage her to go to school on her own next year. (Mother, 9-year-old girl)
I hope these fears will evolve in a positive manner. I will have to force her to face situations such as this last one, in which she
wanted to give up going to the theatre. I will say: Yes, you will go! (Mother, 11-year-old girl)
Her fears will fade away. She will face many difficult situations and learn how to deal with them. (Father, 9-year-old girl)
I think that his fear of darkness will get better if he talks to some specialist. Maybe our family doctor might suggest us someone
specialized in these problems. (Mother, 9-year-old boy)

the child's life. With a more moderate perspective, three fathers and five mothers considered that, although anxiety would be maintained, the child would be able to accommodate and learn to live with it Some of them compared the child's anxiety with their own or their partner's anxiety and concluded that people are able to adapt. In the child's future, anxiety, although stable, will have less impact or consequences.

Contrastingly, one third of the parents, mostly fathers, perceived their children's anxiety as a temporary state, associated with their developmental stage. These parents considered that anxiety symptoms are common in their child's age group and expect that this will decrease with time and maturity.

Finally, nearly a third of the parents considered that the child's anxiety problems would improve. This belief was shared by a similar proportion of fathers and mothers. However, most of them specified that some changes or efforts were necessary to guarantee this improvement. For some, positive changes would result from the parents' intervention, namely, adequate educational strategies. Other parents considered that improvement would occur due to the child's efforts and learning. In some cases, the possibility of improvement was associated with a professional intervention (e.g., physician, teacher, and psychologist).

In conclusion, parents expressed different expectations about the evolution of the child's anxiety. Most mothers expected anxiety to be permanent $(50 \%)$, whereas a smaller number tended to believe that anxiety is transitory (12.5\%) or is possible to improve (37.7\%). Differently, most fathers considered anxiety as a temporary state (54.2\%), whereas a small part tended to believe it to be permanent $(20.8 \%)$ or possible to improve (25\%). Significant differences were found in these beliefs according to parental gender, $\chi^{2}(4,48)=9.73$, $p=0.008$

\subsection{Impact of anxiety}

Eight fathers and six mothers perceived the negative impact of anxiety in many facets of the children's and family's daily lives (Table 4). Some parents worry about the impact that anxiety might have in the future adjustment of their children. One father and three mothers mentioned

TABLE 4 Examples of excerpts of perceptions about the impact of anxiety

Subdimension Excerpts from the interview

Negative

This can have many consequences. He may not be able to study enough to be someone with a good future. (Mother, 12-year-old boy)

It's clearly bad for her because anxiety narrows the way she sees things, isn't it? To be nervous restrains your vision of life. (Father, 9-year-old girl)

I am not worried about how anxiety may hurt him, but I worry about his struggles in the future. He may be unable to make decisions in the future. (Mother, 10-year-old boy)

If this anxiety continues, she might get more isolated and have other possible consequences that I can't even imagine. (Father,

10-year-old girl)

It won't be good at all. She will have no friends. (Mother, 11-year-old girl)

It may inhibit her from experiencing new things, things that are good for her. (Mother, 11-year-old girl)

Anxiety prevents her from appreciating the good things of life. (Mother, 11-year-old girl)

It might become a serious illness. (Father, 10-year-old girl)

If anxiety won't stop, it might be horrible. I think he won't go far in his life. (Father, 9-year-old boy)

She needs us to always be with her. That's tiring for all the family and affects us all ... (Mother, 9-year-old girl)

No impact There isn't any impact. These are normal fears. (Mother, 11-year-old girl)

I think there is no impact. Well, in fact, I never thought much about it. (Mother, 10-year-old girl)

Well, she might feel uncomfortable, but she can handle these situations. (Father, 9-year-old girl)

I am anxious as well. How is that affecting me? Not at all! She and I, we might feel nervous, an upset stomach, our hands sweating and all that stuff, but in the end, we cope with it and the anxiety simply goes away. (Mother, 10-year-old girl)

Positive

He is in the right track! In school, he is a very good student with great results. Being nervous is not bad for him. (Father, 9-yearold boy)

I think it will help her to grow. Feeling worried and anxious will lead her to the right answers in the right moments and that will help her becoming more mature. (Father, 9-year-old girl) 
possible implications in the child's socialization, namely, social isolation. Parents also highlighted that anxiety reduced the child's opportunities to have positive experiences. A few of them expressed more catastrophic expectations about the way anxiety might evolve. One mother identified the negative impact of her child's anxiety on the family.

However, almost one third of the parents considered that anxiety had little or no impact in the child's current functioning. Although in some cases parents recognized that they were not aware of the child's anxiety consequences or simply had never put much thought on this issue, some parents considered that, in spite of some possible emotional impact, children were able to cope or did not avoid the anxiogenic situations. Consequently, parents did not consider it as interfering in the child's functioning. For a few parents, their perception of lack of impact was related to the expectation that anxiety would not affect the child in the future.

Finally, two fathers and one mother believed that anxiety had a positive impact in the child's functioning, associated with positive characteristics of the child (i.e., responsible and hardworking student). Anxiety was also considered a challenge, leading to the improvement of the child's skills and maturity.

In sum, most parents considered that anxiety has a significant negative interference in the child's well-being and future. No significant differences were found in beliefs about the impact of anxiety, according to parental gender, $\chi^{2}(2,48)=0.53, p=0.765$.

\section{4 | Differences between parents who looked for professional help and those who did not}

Quantitative analysis was used to understand if there were differences between the beliefs endorsed by parents who had previously sought some form of professional help for their child's anxiety and those who had not. Twelve parents stated they had sought professional help to treat their child's anxiety complaints.

Chi-square tests evidenced that the beliefs about the causes of anxiety, $\chi^{2}(4,48)=4.69, p=0.320$, and the impact of anxiety, $\chi^{2}(2,48)=1.40, p=0.496$, were not different whether they had sought professional help or not. However, beliefs about the evolution of anxiety showed significant differences between the two groups, $\chi^{2}(2,48)=10.43, p=0.034$. Half of the parents who had sought professional help tended to believe in improvement of anxiety $(50 \%)$, whereas a smaller part was more likely to believe that anxiety is transitory $(25 \%)$ or permanent (8.3\%). Parents who had not sought professional help tended to believe that anxiety would be maintained across time (44.4\%) or was a temporary state (36.1\%), whereas few parents expected that anxiety could improve (19.4\%).

\section{4 | DISCUSSION}

The current study intended to identify and describe parental beliefs about their child's anxiety problems, following an exploratory qualitative approach. A complementary quantitative analysis of data allowed examining if these cognitions were different for mothers and fathers and were related to previous professional help seeking.

Three dimensions were derived from the analyses. The first dimension organizes parental beliefs about the causes of anxiety. Parental causal attributions have been shown to influence parents' behavioral and emotional responses to their child's behavior (Bugental \& Johnston, 2000; Rudy \& Grusec, 2006). In our study, external factors were the most often referred causes. Parents believed that their child's anxiety was a response to external influences, namely, peers' and teacher's pressure, traumatic experiences, or negative events (Rotter, 1990). We hypothesize that this result might be related to a reductionist way of perceiving anxiety as a conditioned response to the environment, put in evidence in previous studies (e.g., King, Clowes-Hollins, \& Ollendick, 1997; Merckelbach, Muris, \& Schouten, 1996). According to Muris and Field (2010), attributions result from people's subjective experiences and, as such, they are influenced by their own beliefs about how fears develop as well as the culture and society where they live. Further, parents might also tend to perceive situations in a threatening manner (e.g., Bugental \& Johnston, 2000). If parents are anxious themselves, they might tend to perceive the world as a risky place and themselves and/or the child as lacking control over the environment (e.g., Becker, Ginsburg, Domingues, \& Tein, 2010). Therefore, parental perceptions of the environment as threatening might reinforce the child's psychological vulnerability and increase her external locus of control, through modelling and information transfer mechanisms (Bugental \& Martorell, 1999; Burks \& Parke, 1996), which constitute risk factors for anxiety development.

Some parents recognized their own role on promoting their child's anxiety through modelling or through parenting rearing styles, particularly referring to overcontrol and overprotection. Parents who tended to believe that their children are vulnerable and fragile may be more overcontrolling and overprotective in order to guarantee the child's safety. As a consequence, parental control behavior increases children's symptoms because it limits children's autonomy and diminishes their sense of mastery and perception of control over stressors (Ballash, Pemble, Buckley, \& Woodruff-Borden, 2006; Chorpita \& Barlow, 1998). Furthermore, parents who referred their own anxiety and negative parenting behaviors (e.g., overprotection) as potential causes for the child's anxiety tended to feel responsible for their child's distress and for the management of the child's problems (Apetroia, Hill, \& Creswell, 2015; Lester, Seal, Nightingale, \& Field, 2010; Reeves, Reynolds, Coker, \& Wilson, 2010; Salkovskis et al., 2000). Nonetheless, they might engage in a "control paradox"; that is, they feel an inflated sense of responsibility about causing and preventing harm to their child, and consequently, respond with excessive control, hoping to reduce the child's distress.

Fewer parents attributed the child's anxiety solely to internal factors. These attributions are in accordance with previous literature that found evidence for the relation between negative attributional styles (stable and global attribution) and internalizing problems (e.g., Bell-Dolan \& Wessler, 1994). It is possible that these parents perceive themselves as less in control over their child's anxiety or even helpless, given their beliefs that anxiety is an inherent and dispositional 
characteristic. We can also speculate that these beliefs about the causes of children's anxiety might be associated, with the child's specific main diagnostic. For instance, generalized anxiety might be attributed to the child's own traits, whereas specific phobia might be attributed to negative events.

Parents who attributed the child's anxiety to an interaction of internal and external/parental factors expressed more complex beliefs in line with theoretical models and research (Chorpita \& Barlow, 1998; Morrisey-Kane \& Prinz, 1999; Sameroff, 2009; Stein, Jang, \& Livesley, 2002) highlighting the dynamic interaction between environmental factors (e.g., stressors, parental influences, and interactions with peers) and the genetic or biological predisposition to anxiety, expressed through temperamental characteristics (e.g., behavioral inhibition, anxiety sensitivity, or fear of negative evaluation).

An alternative perspective was conveyed by parents who perceived anxiety as a normative response. Most of these parents considered that anxiety exerts an adaptive function and perceive some fears and worries as normative during specific stages of development. A few parents also empathized with their child's symptoms and simply accepted them as a natural aspect of life. Although there are common fears and worries during specific stages of the development (e.g., Muris, Merckelbach, \& Collaris, 1997; Ollendick \& King, 1991; Ollendick, Yule, \& Ollier, 1991), these beliefs might blur parents' recognition of anxiety as a problem and lead them to devaluate symptoms that should be recognized as a problem and receive the needed attention and treatment.

The second dimension explored concerned parents' perspectives about the evolution of anxiety. A majority of parents were likely to believe that their child's anxiety would be permanent and last throughout the development. Some parents expected anxiety to be stable without significant fluctuations, whereas others were more pessimistic and considered it would increase. In an intermediate position, some parents expected that the child would simply get used to the anxiety symptoms. Believing that anxiety is long-lasting might promote negative parental behaviors. For instance, parents might engage in overcontrolling parenting as a way to protect and reduce the continuous effects from anxiety in the child (Schleider, Vélez, Krause, \& Gillham, 2014), whereas others may adopt a passive or even helplessness attitude, as they believe that their child's symptoms cannot improve (Alloy et al., 1999). Furthermore, these beliefs may affect parental management of the child's anxiety. Parents might not consider seeking professional help because they believe that it will be useless or unsuccessful.

A considerable number of parents believed that anxiety is a temporary state that will simply go away when the child grows up. Some parents expected some improvement with specific acquisitions (e.g., cognitive development) or life experiences (e.g., increased exposure to social interactions with peers), whereas others had no rational to support these expectations. We may hypothesize that these beliefs prevent parents from worrying, through the minimization of the problem and its impact. However, expecting this "natural" improvement may have several consequences, such as preventing the use of more adaptive coping strategies or delaying the decision to seek professional help, in cases where it would be necessary.
A smaller number of parents revealed a more positive perspective, believing that anxiety problems would be improved with parents' or child's efforts and/or through professional help. These parents recognized the intensity and the negative interference of anxiety in the child's functioning but perceived themselves and/or the child as able to control it. Seeking professional help was one of the strategies mentioned by some parents to overcome these problems.

The last theme referred was the impact of anxiety. In most cases, parents recognized that anxiety had a negative interference in various contexts of the child's functioning (e.g., social adjustment, academic performance, and family relations). Particularly, most parents considered that anxiety compromised the child's current well-being and expected that it could also affect the child's future.

However, a considerable number of parents perceived no significant impact of anxiety in the child's present and future adjustment. This result seems to contradict the classification of interference of anxiety in their child's actual functioning previously obtained in the ADIS. As mentioned in Section 2, only parents who perceived a moderate to high degree of impairment in the child's adjustment resulting from the anxiety problems were interviewed for this study. We hypothesize that parents might have been influenced by the child's perspective during ADIS or that this inconsistency might be a result of different measurement procedures (i.e., rating scale vs. open-ended question). Despite this discordance, this finding suggests that parents might recognize anxiety as a problem but that does not necessary imply the awareness of its impairment in the child's functioning. Besides, some parents might only classify anxiety as a significant problem when symptoms are intense and frequent, rather than moderate. Moreover, some families have adapted their routines to the child's symptoms (e.g., avoiding situations or places that might enhance fearful reactions from the child), which might attenuate the perception of impact. In several cases, parents simply minimized anxiety's impact because of the internalized nature of symptoms (Achenbach, McConaughy, \& Howell, 1987). Furthermore, given that this is a community sample, this result may reflect a reduced recognition of anxiety as a problem.

Curiously, for a few parents, anxiety was associated with positive outcomes. As clinical and empirical experience shows, sometimes, anxious children are socially reinforced for their sense of responsibility and high academic efforts. This parental perception might reflect not only the positive consequences of being anxious, such as having good school's results, but also the internalized and uncovered nature of some symptoms (Sanders et al., 1999). It is possible that these parents associate the perception of anxiety's positive impact with some lack of awareness of the negative consequences and the suffering of the child. Internalizing problems in childhood are perceived by parents as having less impairment than other diagnoses (Angold et al., 1998).

In relation to parental gender, overall fathers and mothers shared similar beliefs about the causes and the impact of the child's anxiety. However, whereas mothers were prone to expect anxiety would be maintained or even aggravated, fathers tended to perceive it as a temporary condition. The higher involvement of mothers in childrearing (Beaujot \& Liu, 2005; Sun \& Roopnarine, 1996) and the consequent proximity to the child might influence their awareness about children's 
symptoms, their frequency, and their consistency across time and situations (e.g., Achenbach et al., 1987).

At last, our findings also suggest that most parents who had previously sought professional help for the child's emotional problems were more likely to believe that anxiety would only improve with their child's efforts and/or professional intervention. In contrast, parents who had not sought professional help tended to believe that anxiety would be maintained across time or that it was a temporary state that would naturally fade away in the future. Contrary to previous studies (e.g., Farmer, Burns, Angold, \& Costello, 1997), the perception of impact was not related to the decision to seek help. This finding might be explained by nonrecognition of anxiety as a severe problem or as not having impact in the family's functioning, given their internalized nature (e.g., Cantwell, Lewinsohn, Rohde, \& Seeley, 1997; Grills \& Ollendick, 2002), parents' reduced reflection about the consequences of children's anxiety, and parent's adaptation to the problem (e.g., allowing avoidance behaviors exhibited by the child; e.g., Lindhout et al., 2006).

\section{1 | Limitations}

The current findings have to be interpreted with caution because of several limitations. First, the homogeneous sample (e.g., in terms of marital status) does not allow generalizing these themes and subthemes to other groups of parents of anxious children. Second, we did not control parents' anxiety, which might have influenced the results. Third, this retrospective study cannot conclude that parental beliefs influenced the professional help seeking. Future prospective studies could confirm if that relation exists previous to intervention. Furthermore, the stability of these beliefs should be addressed in future studies. For instance, it would be important to evaluate these cognitions before, during, and after treatment, and in different stages of the child's development.

\subsection{Implications on science and practice}

Despite these limitations, this study integrates some new contributions to the understanding of the parental role in children's anxiety. First, the inclusion of fathers, usually underrepresented in research (e.g., Van Der Bruggen et al., 2008), allowed to identify some specific gender differences regarding beliefs about anxiety evolution. Second, the qualitative analysis was an important tool to improve our understanding of parental cognitions related to children's anxiety. Future studies and new measures are needed to confirm the role of these beliefs in parenting and anxiety management. Third, our findings provide preliminary evidence for the association between specific parental beliefs (e.g., "child's anxiety is only temporary," "child's anxiety will be there forever," "anxiety will become worst," and "children will get used to anxiety as time goes by") and parental help seeking for anxiety problems in childhood.

Regarding the implications for clinical practice, our findings have potential relevance for the development of family-based interventions to address children's anxiety. Psychoeducation and promotion of adaptive strategies should include cognitive restructuring of parental beliefs based on external control or on self-blame and helpless attitudes towards this problem. Further, preventive programs that include information about how to recognize pathological anxiety and its consequences and pathways of pervasive anxiety symptoms and how anxiety can interfere in the child's functioning should be addressed.

\section{CONFLICT OF INTERESTS}

No conflicts of interest are reported by the authors.

\section{ORCID}

Ana Beato (i) http://orcid.org/0000-0003-3177-3578

\section{REFERENCES}

Achenbach, T. M., McConaughy, S., \& Howell, C. (1987). Child/adolescent behavioral and emotional problems: Implications of cross-informant correlations for situational specificity. Psychological Bulletin, 101, 213-232.

Alloy, L. B., Abramson, L. Y., Whitehouse, W. G., Hogan, M. E., Tashman, N., Steinberg, D., ... Donovan, P. (1999). Depressogenic cognitive styles: Predictive validity, information processing and personality characteristics, and developmental origins. Behaviour Research and Therapy, 37, 503-531.

Alves, S. (2013). Preditores da procura de ajuda profissional: Estudo exploratório com mães de crianças ansiosas (Unpublished master's thesis). Universidade de Lisboa, Lisboa.

Angold, A., Messer, S. C., Stangl, D., Farmer, E., Costello, E. J., \& Burns, B. J. (1998). Perceived parental burden and service use for child and adolescent psychiatric disorders. American Journal of Public Health, 88, 75-80.

Apetroia, A., Hill, C., \& Creswell, C. (2015). Parental responsibility beliefs: Associations with parental anxiety and behaviours in the context of childhood anxiety disorders. Journal of Affective Disorders, 188, 127-133.

Ballash, N. G., Pemble, M. K., Usui, W., Buckley, A., \& Woodruff-Borden, J. (2006). Family functioning, perceived control, and anxiety: A mediational model. Journal of Anxiety Disorders, 20, 486-497.

Beaujot, R., \& Liu, J. (2005). Models of time use in paid and unpaid work. Journal of Family Issues, 26, 924-926.

Becker, K. D., Ginsburg, G. S., Domingues, J., \& Tein, J. Y. (2010). Maternal control behavior and locus of control: Examining mechanisms in the relation between maternal anxiety disorders and anxiety symptomatology in children. Journal of Abnormal Child Psychology, 38, 533-543.

Bell-Dolan, D., \& Wessler, A. E. (1994). Attributional style of anxious children: Extensions from cognitive theory and research on adult anxiety. Journal of Anxiety Disorders, 8, 79-96.

Braun, V., \& Clarke, V. (2006). Using thematic analysis in psychology. Qualitative Research in Psychology, 3, 77-101.

Bugental, D. B., \& Johnston, C. (2000). Parental and child cognitions in the context of the family. Annual Review of Psychology, 51, 315-344.

Bugental, D. B., \& Martorell, G. (1999). Competition between friends: The joint influence of the perceived power of self, friends, and parents. Journal of Family Psychology, 13, 260-273.

Burks, V. S., \& Parke, R. D. (1996). Parent and child representations of social relationships: Linkages between families and peers. Merrill-Palmer Quarterly, 42, 358-378.

Burns, B. J., Costello, E. J., Angold, A., Tweed, D. L., Stangl, D. K., Farmer, E. M. Z., et al. (1995). Children's mental health service use across service sectors. Health Affairs, 14, 147-159.

Cantwell, D. P., Lewinsohn, P. M., Rohde, P., \& Seeley, J. R. (1997). Correspondence between adolescent report and parent report of 
psychiatric diagnostic data. Journal of the American Academy of Child and Adolescent Psychiatry, 36, 610-619.

Cartwright-Hatton, S., Roberts, C., Chitsabesan, P., Fothergill, C., \& Harrington, R. (2004). Systematic review of the efficacy of cognitive behaviour therapies for childhood and adolescent anxiety disorders British Journal of Clinical Psychology, 43, 421-436.

Chorpita, B. F., \& Barlow, D. H. (1998). The development of anxiety: The role of control in the early environment. Psychological Bulletin, 124, 3-21.

Craske, M. G. (1999). Anxiety disorders: Psychological approaches to theory and treatment. Boulder, CO: Westview.

Essau, C. A., Conradt, J., \& Petermann, F. (2000). Frequency, comorbidity and psychosocial impairment of anxiety disorders in German adolescents. Journal of Anxiety Disorders, 14, 263-279.

Essau, C. A., \& Gabbidon, J. (2013). Epidemiology, comorbidity and mental health service utilization. In C. A. Essau, \& T. H. Ollendick (Eds.), The Wiley-Blackwell handbook of the treatment of childhood and adolescent anxiety. Wiley-Blackwell: Chichester.

Farmer, E., Burns, B., Angold, A., \& Costello, E. (1997). Impact of children's mental health problems on families: Relationships with service use. Journal of Emotional and Behavioral Disorders, 5, 230-238.

Francis, S., \& Chorpita, B. (2009). Development and evaluation of the parental beliefs about anxiety questionnaire. Journal of Psychopathology and Behavioral Assessment, 32, 138-149.

Ginsburg, G. S., \& Schlossberg, M. C. (2002). Family-based treatment of childhood anxiety disorders. International Review of Psychiatry, 14, 143-154.

Grills, A. E., \& Ollendick, T. H. (2002). Issues in parent-child agreement: The case of structured diagnostic interviews. Clinical Child and Family Psychology Review, 5, 57-83.

James, A. C., James, G., Cowdrey, F. A., Soler, A., \& Choke, A. (2013). Cognitive behavioural therapy for anxiety disorders in children and adolescents. Cochrane Database of Systematic Reviews, (6). Art. no. CD004690

Keller, M. B., Lavori, R., Wunder, J., Beardslee, W., Schwartz, C., \& Roth, S. (1992). Chronic course of anxiety disorders in children and adolescents. Journal of the American Academy of Child and Adolescent Psychiatry, 31, 595-599.

King, N. J., Clowes-Hollins, V., \& Ollendick, T. H. (1997). The etiology of childhood dog phobia. Behaviour Research and Therapy, 35, 77.

Kortlander, E., Kendall, P. C., \& Panichelli-Mindel, S. M. (1997). Maternal expectations and attributions about coping in anxious children. Journal of Anxiety Disorders, 11, 297-315.

Last, C. G., Hansen, C., \& Franco, N. (1997). Anxious children in adulthood: A prospective study of adjustment. Journal of American Academy of Child and Adolescent Psychiatry, 36, 645-652.

Lester, K. J., Seal, K., Nightingale, Z. C., \& Field, A. P. (2010). Are children's own interpretations of ambiguous situations based on how they perceive their mothers have interpreted ambiguous situations for them in the past? Journal of Anxiety Disorders, 24, 102-108.

Lindhout, I., Markus, M., Hoogendijk, T., Borst, S., Maingay, R., Spinhoven, P., ... Boer, F. (2006). Childrearing style of anxiety-disordered parents. Child Psychiatry and Human Development, 37, 89-102.

Lyneham, H., \& Rapee, R. (2007). Childhood anxiety in rural and urban areas: Presentation, impact and help seeking. Australian Journal of Psychology, 59, 108-118.

McLeod, B. D., Wood, J. J., \& Weisz, J. R. (2007). Examining the association between parenting and childhood anxiety: A meta-analysis. Clinical Psychology Review, 27, 155-172.

Merckelbach, H., Muris, P., \& Schouten, E. (1996). Pathways to fear in spider phobic children. Behaviour Research and Therapy, 34, 935-938.

Micco, J. A., \& Ehrenreich, J. T. (2008). Children's interpretation and avoidant response biases in response to nonsalient and salient situations: Relationships with mothers' threat perception and coping expectations. Journal of Anxiety Disorders, 22, 371-385.
Miles, M. B., \& Huberman, A. M. (1994). Qualitative data analysis. Thousand Oaks, CA: Sage Publications.

Morrisey-Kane, E., \& Prinz, R. (1999). Engagement in child and adolescent treatment: The role of parental cognitions and attributions. Clinical Child and Family Psychology Review, 2, 183-198.

Muris, P., \& Field, A. P. (2010). The role of verbal threat information in the development of childhood fear. "Beware the Jabberwock!". Clinical Child and Family Psychology Review, 13, 129-150.

Muris, P., Merckelbach, H., \& Collaris, R. (1997). Common childhood fears and their origins. Behaviour Research and Therapy, 35, 929-937.

Muris, P., Merckelbach, H., Schmidt, H., \& Mayer, B. (1999). The revised version of the Screen for Child Anxiety Related Emotional Disorders (SCARED-R): Factor structure in normal children. Personality and Individual Differences, 26, 99-112.

NVivo qualitative data analysis Software; QSR International Pty Ltd. Version 10, 2012.

Ollendick, T. H. (1979). Fear reduction techniques with children. In $M$. Hersen, R. M. Eisler, \& P. M. Miller (Eds.), Progress in behavior modification (pp. 127-168). New York: Academic Press.

Ollendick, T. H., \& King, N. J. (1991). Origins of childhood fears: An evaluation of Rachman's theory of fear acquisition. Behaviour Research and Therapy, 29, 117-123.

Ollendick, T. H., Yule, W., \& Ollier, K. (1991). Fears in British children and their relationship to manifest anxiety and depression. Journal of Child Psychology and Psychiatry, 32, 321-331.

Orvaschel, H., Lewinsohn, P. M., \& Seeley, J. R. (1995). Continuity of psychopathology in a community sample of adolescents. Journal of the American Academy of Child and Adolescent Psychiatry, 34, 1525-1535.

Pine, D., Cohen, P., Gurley, D., Brook, J., \& Ma, Y. (1998). The risk for early adulthood anxiety and depressive disorders in adolescents with anxiety and depressive disorders. Archive of General Psychiatry, 55, 56-64.

Reeves, J., Reynolds, S., Coker, S., \& Wilson, C. (2010). An experimental manipulation of responsibility in children: A test of the inflated responsibility model of obsessive-compulsive disorder. Journal of Behavior Therapy and Experimental Psychiatry, 41, 228-233.

Rotter, J. B. (1990). Internal versus external control of reinforcement: Case history of a variable. American Psychologist, 45, 489-493.

Rudy, D., \& Grusec, J. E. (2006). Authoritarian parenting in individualist and collectivist groups: Associations with maternal emotion and cognition and children's self-esteem. Journal of Family Psychology, 20, 68-78.

Salkovskis, P. M., Wroe, A. L., Gledhill, N., Morrison, N., Forrester, E., Richards, M., ... Thorpe, S. (2000). Responsibility attitudes and interpretations are characteristic of obsessive compulsive disorder. Behaviour Research and Therapy, 38, 347-372.

Sameroff, A. J. (Ed.) (2009). The transactional model of development: How children and contexts shape each other. Washington, DC: American Psychological Association.

Sanders, M. R., Tully, L. A., Baade, P. D., Lynch, M. E., Heywood, A. H., Pollard, G. E., \& Youlden, D. E. (1999). A survey of parenting practices in Queensland: Implications for mental health promotion. Health Promotion Journal of Australia, 9, 105-114.

Schleider, J. L., Vélez, C. E., Krause, E. D., \& Gillham, J. E. (2014). Perceived psychological control and anxiety in early adolescents: The mediating role of attributional style. Cognitive Therapy and Research, 38, 71-81.

Silverman, W., \& Albano, A. (1996). The anxiety disorders interview schedule for children-IV (child and parent versions). San Antonio, TX: Psychological Corporation.

Stein, M. B., Jang, K. L., \& Livesley, W. J. (2002). Heritability of social anxiety-related concerns and personality characteristics: A twin study. The Journal of Nervous and Mental Disease, 190, 219-224.

Sun, L. C., \& Roopnarine, J. L. (1996). Mother-infant, father-infant interaction and involvement in childcare and household labor among Taiwanese families. Infant Behavior and Development, 19, 121-129. 
Tesch, R. (1990). Qualitative research: Analysis types and software tools. New York: Falmer.

Van Der Bruggen, C. O., Stams, G. M., \& Bögels, S. M. (2008). Research review: The relation between child and parent anxiety and parental control: A meta-analytic review. Journal of Child Psychology and Psychiatry, 49, 1257-1269.

Vasey, M. W., \& Dadds, M. R. (2001). The developmental psychopathology of anxiety. New York: University Press.

Wheatcroft, R., \& Creswell, C. (2007). Parents' cognitions and expectations about their pre-school children: The contribution of parental anxiety and child anxiety. The British Journal of Developmental Psychology, 25, 435-441.
Zwaanswijk, M., Verhaak, P. F., Bensing, J. M., van der Ende, J., \& Verhulst, F. C. (2003). Help seeking for emotional and behavioural problems in children and adolescents: a review of recent literature. European Child \& Adolescent Psychiatry, 12(4), 153-161.

How to cite this article: Beato A, Barros L, Pereira Al. Father's and mother's beliefs about children's anxiety. Child Care Health Dev. 2018;44:784-793. https://doi.org/10.1111/cch.12603 